\title{
Áreas verdes e risco de desastres nas eleições municipais de 2016: propostas de candidatos em municípios paulistas e
}

\section{catarinenses}

\begin{abstract}
Resumo
A manutenção da vegetação no âmbito municipal é fundamental para a redução de riscos de desastres e para a manutenção do equilíbrio ambiental. Nesse contexto, avaliamos propostas de candidatos que concorreram às eleições municipais de 2016, em municípios dos estados de São Paulo e Santa Catarina monitorados quanto ao risco de desastres socioambientais. Para tanto, verificamos se os candidatos de dez municípios (cinco de cada estado), consideraram em suas propostas os seguintes temas: i) importância das áreas verdes na melhoria das condições ambientais das cidades; ii) interesse em fiscalizar áreas de risco; iii) regularização urbana, no contexto da redução de risco e conservação de áreas verdes municipais. Os resultados mostram que os candidatos reconhecem a importância da vegetação, a exemplo do aumento da permeabilidade do solo e proteção dos recursos hídricos. Por outro lado, a fiscalização, para evitar a formação de áreas de risco e a degradação da vegetação, foi apresentada em menos da metade das propostas. A regularização de áreas continua a ser um problema, pois a maior parte dos candidatos pretende realizá-la, independente dos riscos e problemas futuros que possa causar aos moradores e ao poder público. Além disso, há escassa participação de mulheres nos pleitos eleitorais municipais analisados.
\end{abstract}

Palavras-chave: Eleições Municipais. Áreas Verdes. Desastres Socioambientais. Proteção Ambiental.

\section{Marcos Pellegrini Coutinho}

Mestre em Produção Vegetal pela Universidade Estadual do Norte Fluminense Darcy Ribeiro UENF. Pesquisador do Centro Nacional de Monitoramento e Alerta de Desastres - CEMADEN. Brasil

mzpcoutinho@yahoo.com.br

\section{Luciana de Resende Londe}

Doutora em Sensoriamento Remoto pelo Instituto Nacional de Pesquisas Espaciais - INPE.

Pesquisadora do CEMADEN. Brasil

luciana.londe@cemaden.gov.br

\section{Érico Soriano}

Doutor em Ciências pela Univ. de São Paulo - USP. Pesquisador Associado na Univ. Federal de

São Carlos - UFSCar. Brasil

ericogeo@gmail.com

\section{Demerval Aparecido Gonçalves}

Mestre em Ciências pelo Instituto Tecnológico de Aeronáutica - ITA.

Pesquisador bolsista do CEMADEN.

Brasil

demervas@gmail.com

\section{Paulo Jorge Vaitsman Leal} Doutor em Geografia pela Univ. Federal do RJ - UFRJ. Professor Univ. Federal Fluminense - UFF Brasil pjvleal@id.uff.br 


\title{
Green areas and disaster risk in the 2016 municipal elections: proposals from candidates of São Paulo and Santa Catarina municipalities
}

\begin{abstract}
The presence of vegetation in urban areas is important for disaster risk reduction and environmental balance. In this context, we evaluated proposals for the 2016 Brazilian municipal elections, for municipalities monitored regarding socio-environmental disaster risks in São Paulo and Santa Catarina states. We analyzed proposals from ten municipalities (five from each state) about: i) importance of vegetation in improving the environmental conditions of cities; ii) interest in supervising risk areas; iii) urban regulation, in the context of risk reduction and conservation of green areas in the cities. The results show that candidates recognize the importance of vegetation in the cities, such as increased soil permeability and protection of water resources, functions performed by vegetation that supports disaster risk reduction. On the other hand, the monitoring aiming to avoid the creation of new risk areas and degradation of vegetation, was presented in less than half of the proposals. The regularization of areas continues to be a problem, since most candidates intend to carry it out, irrespective of the risks and future problems to residents and public power. Few women were candidates in the analyzed municipalities.
\end{abstract}

Keywords: Mayoral Candidates. Green Areas. Socioenvironmental Disasters. Environmental Protection.

\section{Para citar este artigo:}

COUTINHO, Marcos Pellegrini; LONDE, Luciana de Resende; SORIANO, Érico; GONÇALVES, Demerval Aparecido; LEAL, Paulo Jorge Vaitsman. Áreas verdes e risco de desastres nas eleições municipais de 2016: propostas de candidatos em municípios paulistas e catarinenses. Revista PerCursos, Florianópolis, $\mathrm{v}$. 18, n.36, p. $175-193$, jan./abr. 2017.

\section{DOI: $10.5965 / 1984724618362017175$}

http://dx.doi.org/10.5965/1984724618362017175 


\section{Introdução}

O processo de urbanização no Brasil, em geral, conduziu à formação de aglomerações urbanas e regiões metropolitanas, principalmente na segunda metade do século XX (GROSTEIN, 2001). Esta formação gerou áreas de risco de desastres socioambientais, a exemplo das várzeas inundáveis que, como consequência, causam prejuízos humanos e materiais (TUCCI, 2005).

Atualmente, as cidades podem apresentar um crescimento urbano mais sustentável, de forma organizada, com melhores condições de vida e menos exposição aos riscos por parte da população, caso a expansão urbana ocorra de forma planejada e sem privilégios à especulação imobiliária. Nesse sentido, menciona-se o atual Código Florestal (Lei 12.651/2012), o Estatuto da Cidade (Lei 10.257/2001) e a Lei de Parcelamento do Solo (Lei 6.766/1979), que são formas de induzir um processo adequado de ocupação do ambiente, sobretudo no que se refere às Áreas de Preservação Permanente (APP). Para tanto, os administradores e atores locais devem seguir determinações impostas na legislação (Código Florestal, Estatuto das Cidades e outras) e nas cartas geotécnicas (indicação da adequação dos terrenos), quando disponíveis, atuando para inibir ocupações em áreas inadequadas ao processo de expansão urbana, como áreas protegidas, de várzeas, margens de rios, nascentes, entre outras, além de atuarem na conservação e recuperação destas áreas.

É possível prever as direções preferenciais do crescimento urbano e verificar dados de geologia, pedologia e recursos hídricos para estes locais. A partir dessas análises é possível redirecionar a expansão das cidades para áreas mais adequadas (SPERANDELLI, 2010) e, ainda, elaborar um zoneamento da área a ser ocupada, com vista à redução de danos ambientais e riscos de desastres socioambientais, pensando nos limites impostos pelo relevo, hidrografia e necessidade de conexão da vegetação nativa. Todavia, a fiscalização da aplicação do Código Florestal pelos governantes municipais é fraca e, às vezes, até mesmo apresenta ações antagônicas (COUTINHO et al., 2013), quando deveria evitar a ocupação dessas áreas em função dos riscos associados 
(inundações e deslizamentos) e de sua importância à biodiversidade, na ocasião da expansão urbana ou revitalização das cidades.

Denaldi (2010) recomenda que as ações de urbanização e regularização sejam integradas desde o início do processo e que as intervenções físicas sejam norteadas por diretrizes integradas, elaboradas a partir de um diagnóstico que incorpore aspectos urbanísticos, ambientais, sociais e fundiários.

Tendo em vista que as ocupações urbanas desordenadas ou decorrentes de especulação imobiliária são o principal fator de geração de novas áreas de risco e do aumento da vulnerabilidade a desastres socioambientais, e que no ano de 2016 foram realizadas eleições municipais, o objetivo do presente trabalho foi levantar e discutir as medidas propostas por candidatos a prefeito em relação à importância da conservação das áreas verdes nas cidades, no âmbito da expansão urbana e da redução de risco de desastres socioambientais. Para corresponder a este objetivo, foi feita uma análise qualitativa e quantitativa das informações apresentadas nos planos de governos apresentados pelos candidatos a prefeitos dos municípios monitorados com risco de desastres socioambientais e, portanto, com problemas recorrentes quanto à temática, como áreas suscetíveis e população vulnerável a processos hidrológicos e a movimentos de massa.

\section{Metodologia}

Levantamos e avaliamos as propostas de candidatos que concorreram ao cargo de prefeito de municípios monitorados quanto ao risco de desastres socioambientais, dos estados de São Paulo e Santa Catarina. A definição dos estados e municípios levou em consideração a quantidade de alertas enviados pelo Centro Nacional de Monitoramento e Alerta de Desastres Naturais- CEMADEN, nos últimos anos, conforme Figura 1. 


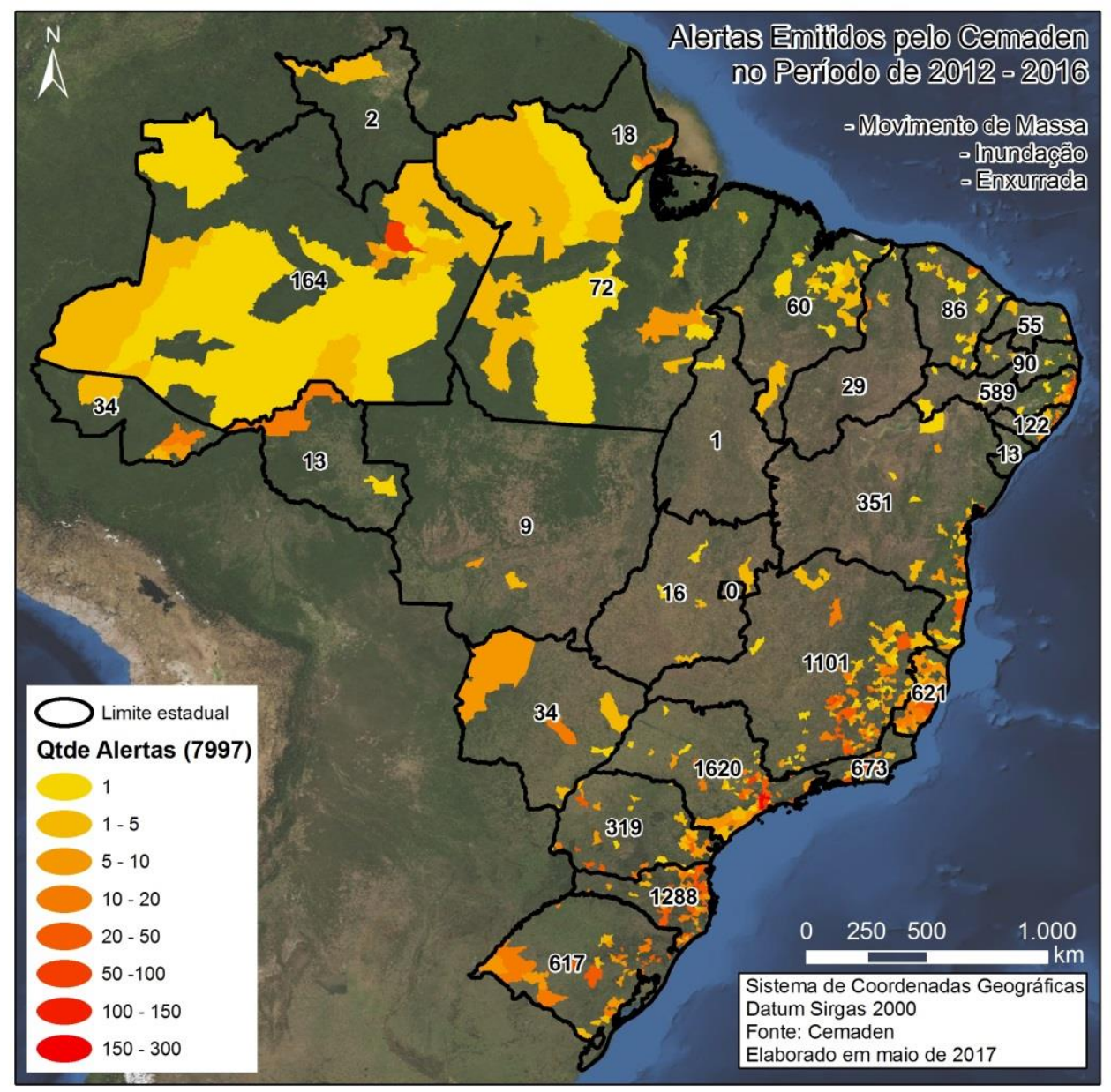

Figura 1 - Estados e alertas emitidos pelo Cemaden. Fonte: CEMADEN.

As propostas dos municípios que mais receberam alertas do CEMADEN dos dois estados foram consultadas no site do "DivulgaCand", do Tribunal Superior Eleitoral- TSE. Analisamos se os candidatos consideraram: i) importância das áreas de preservação permanente, incluindo a proteção de mananciais, relevância das áreas verdes, parques, e medidas para recuperar tais áreas; ii) o interesse em fiscalizar áreas de risco, evitando sua ocupação e riscos associados; iii) regularização urbana, no contexto da redução de risco e conservação de áreas verdes nas cidades.

Atribuímos as categorias o (zero) para ausência de informação e 1 (um) para as ocasiões em que os temas foram mencionados. Os valores percentuais e demais números foram trabalhados em planilha eletrônica. 
Apresentamos nas discussões trechos de propostas que abordaram de forma consistente os três itens avaliados. Na sequência, foi organizada a tabela 1, com os valores percentuais, resultantes da somatória de pontos dos candidatos (três itens avaliados) e quantidade de candidatos por município, que variou de três (municípios de Camboriú, Itajaí e Rio do Sul) a 11 (São Paulo). Também apresentamos a tabela 2, com os resultados das propostas por partido.

\section{Resultados e Discussão}

Como pôde ser observado na Figura 1, todos os municípios analisados apresentam um histórico recente de ocorrência de precipitações que representaram riscos de desastres socioambientais.

Dos 56 candidatos analisados, apenas sete (12,5\%) não apresentaram propostas ou não pontuaram em nenhum dos itens avaliados, sendo duas referentes a São Paulo, Taboão da Serra e Brusque e uma de São Bernardo do Campo. Dos 56 candidatos, apenas quatro eram mulheres, assim distribuídas: duas concorreram ao município de São Paulo, uma em Itajaí e uma em Ubatuba. A baixa participação feminina na disputa eleitoral municipal revela que a cultura política e de gênero são entraves para maior discussão e mudanças reais na participação da mulher na esfera pública (LIMA, 2015).

Os resultados mostram que os candidatos deram mais atenção ao tema 1, com destaque para os municípios de Cubatão, Ubatuba, Blumenau, Camboriú e Itajaí, onde todos os candidatos abordaram a importância das áreas verdes (parques, matas ciliares, áreas verdes) nas cidades (Tabela 1). Nesse tópico, também cabe destacar propostas de São Paulo e Rio do Sul, com valores percentuais de 72,7 e 66,6\%, respectivamente. 
Tabela 1 - Valores absolutos e percentuais referentes às propostas avaliadas.

\begin{tabular}{|c|c|c|c|c|c|}
\hline \multirow[t]{2}{*}{ Municípios } & \multirow{2}{*}{$\begin{array}{c}\mathbf{N}^{\circ} \text { de } \\
\text { candidatos }\end{array}$} & \multicolumn{3}{|c|}{$\begin{array}{c}\text { Questões } \\
\text { (desenvolvimento) }\end{array}$} & \multirow{2}{*}{$\begin{array}{r}\text { Valor } \\
(\%)\end{array}$} \\
\hline & & $\mathrm{i}$ & ii & iii & \\
\hline \multicolumn{6}{|c|}{ Estado de São Paulo } \\
\hline Cubatão & 5 & 5 & 3 & 4 & 80,0 \\
\hline São Bernardo do Campo & 6 & 4 & 5 & 3 & 66,6 \\
\hline São Paulo & 11 & 8 & 6 & 6 & 60,6 \\
\hline Taboão da Serra & 6 & 3 & 1 & 2 & 33,3 \\
\hline Ubatuba & 7 & 7 & 5 & 6 & 85,7 \\
\hline \multicolumn{6}{|c|}{ Estado de Santa Catarina } \\
\hline Blumenau & 5 & 5 & 2 & 4 & 80,0 \\
\hline Brusque & 7 & 4 & 1 & 1 & 28,5 \\
\hline Camboriú & 3 & 3 & 2 & 1 & 66,6 \\
\hline Itajaí & 3 & 3 & 1 & 2 & 66,6 \\
\hline Rio do Sul & 3 & 2 & 0 & 2 & 44,4 \\
\hline Soma (Percentual) & $56(100)$ & 78,6 & 46,4 & 55,4 & 60,1 \\
\hline
\end{tabular}

Considerando-se a totalidade das propostas, as questões ii (fiscalização) e iii (regularização) analisadas, apresentaram valores percentuais próximos, sendo mais elevados para regularização (55,4 \%), ambos de interesse de candidatos e munícipes. 
Tabela 2 - Síntese dos resultados por partido e itens avaliados.

\begin{tabular}{|c|c|c|c|c|c|c|c|c|c|c|c|c|c|c|}
\hline \multirow[b]{2}{*}{ 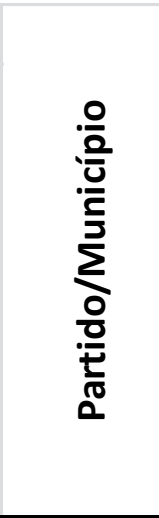 } & \multicolumn{5}{|c|}{ São Paulo } & \multicolumn{5}{|c|}{ Santa Catarina } & \multirow[b]{2}{*}{$\begin{array}{l}\text { Ũ } \\
\frac{0}{\pi} \\
\frac{\pi}{0} \\
\frac{0}{0} \\
\frac{0}{0} \\
\frac{0}{0} \\
\frac{0}{\pi} \\
0 \\
0\end{array}$} & \multicolumn{3}{|c|}{ Questões } \\
\hline & $\begin{array}{l}\stackrel{0}{10} \\
\stackrel{10}{\pi} \\
\stackrel{0}{3} \\
\end{array}$ & 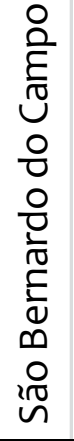 & $\begin{array}{l}\frac{0}{7} \\
\frac{0}{0} \\
0 \\
0 \\
\sim \\
\sim\end{array}$ & 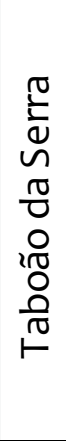 & 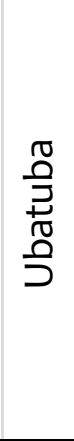 & 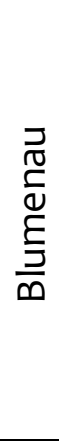 & 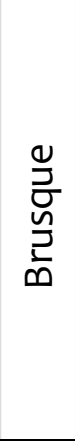 & 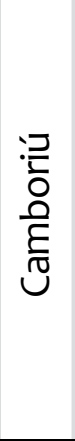 & $\frac{\sqrt[\pi]{\pi}}{ \pm}$ & $\begin{array}{l}\bar{\Xi} \\
0 \\
0 \\
0 \\
\frac{0}{\sim}\end{array}$ & & $\mathrm{i}$ & ii & iii \\
\hline PMDB & $x$ & $x$ & $x$ & & $x$ & & & $x$ & $x$ & $x$ & 7 & 7 & 3 & 5 \\
\hline PSDB & $x$ & $x$ & $x$ & $x$ & $x$ & $x$ & & $x$ & $x$ & $\bar{x}$ & 9 & 7 & 6 & 7 \\
\hline PT & $x$ & $x$ & $x$ & & $x$ & $x$ & $x$ & & & $x$ & 7 & 6 & 4 & 5 \\
\hline PSOL & & $x$ & $x$ & $x$ & $x$ & & $x$ & & & & 5 & 4 & 1 & 2 \\
\hline REDE & & & $x$ & & & & & & & & 1 & 1 & 1 & 0 \\
\hline SD & $x$ & & $x$ & & & & $x$ & & & & 3 & 3 & 1 & 2 \\
\hline PRTB & & & $x$ & & & & & & & & 1 & 0 & 0 & 0 \\
\hline PCO & & & $x$ & & & & & & & & 1 & 0 & 0 & 0 \\
\hline PSDC & & & $x$ & & & & & & & & 1 & 1 & 1 & 0 \\
\hline PRB & & & $x$ & & & & & & & & 1 & 0 & 1 & 1 \\
\hline PSTU & & $x$ & $x$ & & & & & & & & 2 & 0 & 0 & 0 \\
\hline PSB & $x$ & & & $x$ & $x$ & & $x$ & & & & 4 & 2 & 1 & 1 \\
\hline PTB & & & & & $x$ & & & & & & 1 & 1 & 1 & 1 \\
\hline PSD & & & & $x$ & $x$ & $x$ & & $x$ & & & 4 & 3 & 2 & 2 \\
\hline PV & & & & $x$ & & & & & & & 1 & 1 & 0 & 1 \\
\hline PSL & & & & $x$ & & & & & & & 1 & 1 & 1 & 1 \\
\hline PPS & & $x$ & & & & & & & & & 1 & 1 & 1 & 0 \\
\hline PC do B & & & & & & $x$ & & & & & 1 & 1 & 0 & 1 \\
\hline PDT & & & & & & $x$ & & & & & 1 & 1 & 0 & 1 \\
\hline PP & & & & & & & $x$ & & $x$ & & 2 & 2 & 1 & 1 \\
\hline DEM & & & & & & & $x$ & & & & 1 & 1 & 0 & 0 \\
\hline PROS & & & & & & & $x$ & & & & 1 & 1 & 1 & 0 \\
\hline Soma & 5 & 6 & 11 & 6 & 7 & 5 & 7 & 3 & 3 & 3 & 56 & 44 & 26 & 31 \\
\hline
\end{tabular}

$\mathbf{x}$ candidatos com plano 


\section{Desenvolvimento urbano, vegetação e áreas de risco}

O crescimento desordenado ou excludente dificulta compatibilizar as áreas construídas com as vegetadas (OLIVEIRA et al., 2013), o que pode representar a diminuição da qualidade de vida nas cidades.

Nas cidades com áreas suscetíveis à ocorrência de desastres socioambientais, os agentes públicos e privados, promotores do crescimento urbano, deverão coibir a ocupação de áreas de risco, conforme especificações da Política Nacional de Proteção e Defesa Civil (PNPDEC), de forma a construir cidades resilientes e processos sustentáveis de urbanização.

Para tanto, os planos diretores (PD), em elaboração ou em processo de atualização, deverão especificar as áreas de risco e impor condicionantes ao crescimento da cidade naquelas direções. Entre as áreas urbanas e rurais que necessitam de atenção, além das áreas de risco mapeadas por órgãos oficiais, estão as nascentes, margens de cursos d'água e outros espaços de interesse ecológico, com necessidade de ter a vegetação recomposta e conservada. Observa-se, em vários casos, que as áreas de Preservação Permanente (APP), como margens de rios, apresentam alto risco de serem atingidas por fluxos de escombros que contêm troncos, além de serem os primeiros locais a serem inundados em épocas de cheia (KOBIYAMA et al., 2012; 2010).

Áreas de risco podem ser transformadas em espaços de lazer, quando não oferecerem segurança aos habitantes, a partir da gestão e priorização de ações por parte da administração. Insere-se nesse contexto a recomposição da vegetação de áreas municipais a serem requalificadas, detalhadas em planos específicos. Parte dos candidatos abordou em suas propostas essa perspectiva, conforme trechos a seguir apresentados:

Promover ações intersetoriais, articulando diferentes secretarias municipais, conselhos, organizações governamentais e não governamentais, instituições educacionais e iniciativa privada no sentido de incentivar o consumo consciente, a reciclagem, o não desperdício e a preservação do meio ambiente, incluindo a não ocupação de áreas de risco 
e conservação da mata ciliar. (Proposta de candidato do PT à prefeitura de Blumenau)

Entendemos que a preservação e a ampliação das áreas verdes na cidade de São Paulo são iniciativas importantes para equilibrar o microclima local e amenizar os efeitos do aquecimento global, reduzir a poluição atmosférica e sonora, aumentar a permeabilidade do solo e reduzir os riscos de enchentes. (Proposta de candidata do PSOL à prefeitura de São Paulo)

Ampliar praças e parques visando à requalificação do espaço urbano. (Proposta de candidato do PSDB à prefeitura de Blumenau)

Agregar, ao Plano Diretor, novas formas de uso e ocupação do solo, vinculadas organicamente a uma nova dinâmica de funcionamento da cidade, que privilegie a proteção, preservação e recuperação do meio ambiente natural e construído, do patrimônio cultural, histórico, artístico, paisagístico e arqueológico. (Proposta de candidato do PSOL à prefeitura de Brusque)

Criar parcerias com os Governos Estadual e Federal para intensificar a vigilância nas Áreas de Preservação Permanente, visando impedir invasões ou agressões ao ecossistema. (Proposta de candidato do SD à prefeitura de Cubatão)

Outros candidatos abordaram o desassoreamento de rios, saneamento e planos de drenagem considerando a bacia hidrográfica, aspectos fundamentais para melhorar as condições ambientais e reduzir a poluição de cursos d'água e a ocorrência de inundações.

Intensificar os trabalhos de macrodrenagem, limpeza, desassoreamento e proteção das margens dos rios e ribeirões que compõem as principais bacias hidrográficas. (Proposta de candidato do PT à prefeitura de Blumenau)

Saneamento ambiental por microbacias, aumento das áreas permeáveis, gestão das águas e recuperação de rios e nascentes. (Proposta de candidata do PSOL à prefeitura de São Paulo) 
Também houve propostas abordando a conservação de represas (mananciais) e a recuperação da Mata Atlântica.

Desenvolver o PMMA - Plano Municipal da Mata Atlântica (ampliar, aprimorar, uma vez que está prevista a construção do Plano de Ação esse ano). (Proposta de candidata do PSOL à prefeitura de São Paulo)

Criar o plano municipal de conservação e recuperação da mata atlântica, recuperação da mata ciliar, delimitando as áreas de interesse ambiental, prioritárias para a preservação. (Proposta de candidato do PSDB à prefeitura de Blumenau)

As áreas verdes podem fazer parte das áreas de expansão urbana, aproveitando áreas de vegetação nativa, conforme a Lei 12.651, de 2012 (Código Florestal), e vazios urbanos, como margens de rios ou outras sem aptidão para urbanização. Uma relação adequada entre áreas verdes e população é importante, pois as áreas verdes minimizam os efeitos da impermeabilização, regulam o microclima, amenizando as altas temperaturas produzidas pela concentração de áreas edificadas ou pavimentadas (OLIVEIRA et al., 2013).

Com análise de dados da população e do meio físico, podemos indicar os espaços mais adequados à ocupação e conservação, permitindo antecipar e não gerar os riscos de desastres. Concordamos com Sperandelli (2010) ao descrever que é viável prever as direções preferenciais do crescimento urbano e analisar variáveis ambientais para esses locais. A partir dessas análises, pode-se propor o direcionamento das cidades para áreas mais adequadas. Nessa linha, alguns municípios têm criado parques lineares em APP, com integração de rios, vegetação e infraestrutura urbana, gerando espaços de lazer aos moradores e revitalizando áreas urbanas.

Observamos que alguns municípios também podem utilizar a carta geotécnica, imprescindível na orientação da expansão urbana e na identificação de áreas inaptas à urbanização. Entre os dez municípios aqui analisados, apenas quatro (Blumenau, São 
Paulo, São Bernardo do Campo e Taboão da Serra) tinham cartas geotécnicas elaboradas até 2013, segundo o banco de dados do Perfil dos Municípios Brasileiros (IBGE, 2014).

O fato de várias cidades sofrerem com falta de água e enchentes nos últimos anos, e o processo de discussão do Código Florestal, ajuda a explicar o posicionamento dos candidatos quanto à importância de se trabalhar a conservação e recuperação da vegetação nativa nas áreas urbanas e municípios. Mesmo não sendo totalmente aceito por partidos de direita, centro-direita e bancada ruralista, o Código Florestal não foi desconsiderado pelos candidatos na ocasião da elaboração das propostas e, inclusive, alguns candidatos, como do PSDB em Ubatuba e PMDB em Cubatão, mencionaram ampliar a proteção e conservação das nascentes, rios e outras áreas protegidas.

\section{Fiscalização e Riscos}

A especulação imobiliária, falta de ordenamento territorial e de fiscalização, na maior parte dos municípios, vem ocasionando a ocupação de áreas de risco e, para lidar com o problema, os municípios devem elaborar planos de intervenções e contingência, além de contar com um sistema de monitoramento e de defesa civil para atender às emergências (DENALDI, 2010).

Na maior parte dos municípios brasileiros a defesa civil tem concentrado seus esforços nas atividades de resposta (LONDE et al., 2014), deixando de lado medidas preventivas não estruturais como a fiscalização, por gerar conflitos e não ter apoio do poder público local (administrativo e legislativo), que está preocupado com futuras eleições.

Os candidatos que mais mencionaram utilizar a fiscalização para evitar a ocupação em áreas de risco e inadequadas foram os de São Bernardo do Campo (com valor percentual de 83,3\%), Ubatuba (71,4 \%), Cubatão (60,0 \%) e São Paulo (54,5 \%). Dos partidos com mais representantes no Congresso, os candidatos do PSDB foram os que mais desenvolveram o tema. Além disso, outros partidos, como REDE, PTB, PSL, entre outros, com candidato em apenas um município, também, abordaram o assunto. Nesse campo, selecionamos os seguintes trechos de propostas: 
Fiscalização e monitoramento institucional e comunitário, visando coibição de ocupações irregulares. (Proposta de candidato do PSDB à prefeitura de Ubatuba)

Fortalecer as ações da Defesa Civil na prevenção e resposta a desastres naturais, inibindo ocupações irregulares. (Proposta de candidato do PP à prefeitura de Itajaí)

Avaliar os locais de risco e inibir as invasões através de Políticas Públicas Sustentáveis e de Inclusão. (Proposta de candidato do PSB à prefeitura de Cubatão)

Atuar de maneira efetiva nas áreas de proteção, deter a degradação e a extinção de áreas verdes, além de carecer de uma visão integrada e de longo prazo da preservação ambiental. (Proposta de candidato do PSDB à prefeitura de São Bernardo do Campo)

Implantar normas e critérios rigorosos de fiscalização das atividades ilegais dos loteadores de terras e ocupantes de áreas de risco. (Proposta de candidato do PT à prefeitura de Blumenau)

Fortalecer as ações de fiscalização das áreas com potencial de risco maior, evitando o crescimento destas áreas e viabilizando soluções para as áreas já existentes de forma integrada com o Plano Municipal de Habitação de Interesse Social. (Proposta de candidato do PSDB à prefeitura de Blumenau)

Os municípios são responsáveis por impedir a ocupação em áreas de risco especificada na PNPDEC (Lei 12.608, de 2012), contando com estruturas institucionais (controle urbano, meio ambiente, defesa civil, entre outras), que podem atuar em conjunto para esse fim. Também é possível e desejável construir diálogos com a população, aproximando as comunidades das resoluções de seus problemas. Para estimular denúncias por parte da população, sugerimos a criação de linhas diretas com a instituição responsável, bem como a criação e disponibilização de aplicativos que facilitem a denúncia de formação e ocupações em áreas de risco. 
Os candidatos de São Bernardo do Campo e Ubatuba articularam melhor suas propostas ( 83 e $71 \%$, respectivamente) em relação às ações de fiscalização. Para explicar tais percentuais, mencionamos que São Bernardo do Campo apresenta 53,7\% de sua área municipal como sendo de proteção aos mananciais. Em Ubatuba parte considerável do território localiza-se em áreas protegidas, sendo 85 \% dele coberto por vegetação da Mata Atlântica. Em tais municípios, constantemente, áreas com vegetação, incluindo protegidas, são pleiteadas pelo setor privado para abertura de novos empreendimentos (especulação imobiliária), conforme Barbosa, Formagio e Barbosa (2010) e SÃO PAULO (2014).

Por outro lado, em Taboão da Serra, Itajaí e Rio do Sul, as propostas deixaram de abordar a fiscalização e importância desse instrumento no ordenamento do território. Soriano et al. (2013), avaliando propostas de candidatos a prefeitos em relação aos riscos de desastres, descrevem que a desconsideração destes temas pode guardar uma relação direta com a ausência de políticas eficientes e de investimentos públicos para a redução de riscos e da vulnerabilidade de parcelas da população.

\section{Riscos e Regularização}

A transformação urbana implica processos mais complexos que as práticas atuais de regularização de parcelamentos ou urbanização de favelas (GROSTEIN, 2001). Segundo a autora, a regularização dos locais informais, devido à relevância das questões ambientais e interesses da população, envolve a necessidade de preservar a qualidade da água, de defender as áreas de proteção ambiental, ou mesmo a defesa de parques urbanos ou espaços verdes.

Todavia, na maioria dos casos, temos intervenções realizadas pelo poder público nos assentamentos informais que garantem apenas a regularização fundiária, independente das condições urbanísticas e ambientais (CALDAS, 2009).

Observamos, em muitas propostas, que os candidatos pretendem estimular a regularização sem estabelecer critérios e buscar melhorias para tais áreas, corroborando o que dizem as autoras supracitadas. O intuito é regularizar para aumentar a arrecadação 
municipal, por meio do IPTU, conforme trecho da primeira proposta apresentada a seguir. Entretanto, também, destacamos propostas bem estruturadas quanto à regularização:

Criar uma via rápida para a regularização fundiária por meio da criação de instâncias decisórias colegiadas com representantes das diversas secretarias envolvidas...

Providenciar a imediata inserção dos lotes regularizados no cadastro fiscal. (Proposta de candidata do PMDB à prefeitura de São Paulo)

Recuperar espaços abandonados e edifícios desocupados para funcionar como moradia. Atender famílias situadas em áreas de risco e de mananciais, promovendo a recuperação ambiental dessas áreas. (Proposta de candidata do PMDB à prefeitura de São Paulo)

Instituir política pública de regularização fundiária de assentamentos urbanos irregulares e de realocação total ou parcial da população, de forma integrada com o Plano Municipal de Habitação de Interesse Social. (Proposta de candidato do PSDB à prefeitura de Blumenau)

Promover uma moradia digna, regularizando os imóveis e seus registros, garantindo que ninguém viva em área de risco e sem os documentos de propriedade. (Proposta de candidato do PP à prefeitura de Brusque)

Quando a regularização ocorre sem critérios, grupos vulneráveis recebem aval da administração para continuar em áreas de risco e com problemas ambientais. Todavia, a regularização fundiária fora de áreas de risco geológico e ambiental permite a manutenção dos serviços essenciais, como coleta do lixo, varrição das ruas e iluminação pública, elevando o padrão das edificações (MARICATO, 2008). Para a autora, em função de condicionantes financeiras, sociais e políticas, a urbanização gradual, é a modalidade que mais tem sido adotada pelos governos municipais e a que beneficia maior percentual da população de favelas.

Os municípios, onde vários problemas socioambientais e riscos são deflagrados, necessitam de ações direcionadas do poder público para se tornarem resilientes. Além de outras demandas urgentes (educação, cultura, saúde, segurança, etc.), cabe ao 
representante local, entre outras atribuições, atualizar o plano diretor, com especificação dos locais, áreas e zonas de risco, além de fiscalizar para que tais áreas não estejam disponíveis à população e, se possível, quando não habitáveis, que tenham suas funções ecológicas restabelecidas, por meio da recomposição da vegetação.

\section{Considerações Finais}

A regularização fundiária, ao contrário da ideia de remoção, propõe aceitar o que a sociedade produziu à margem dos parâmetros legais e, no caso da regularização urbanística-ambiental, incorporar esses espaços ao ambiente urbano "oficial", adequando-os minimamente a uma situação de acesso à infraestrutura básica e de erradicação de riscos (SPINAZZOLA, 2008). Nesse contexto, a regularização fundiária deve ser abrangente, avaliando os riscos e o ambiente que precisa ser recuperado (mata ciliar, nascentes e outras) e ir além do reconhecimento do direito à moradia.

A preservação, conservação e recuperação de áreas verdes reduz o escoamento superficial em áreas urbanas, com maior infiltração de água no solo e, consequentemente, evita processos erosivos e minimiza os efeitos das enchentes e inundações.

Os candidatos a prefeito nos estados de São Paulo e Santa Catarina, em geral, reconheceram a importância das áreas verdes no âmbito da redução de risco, aspecto fundamental para alcançarmos cidades mais resilientes. Por outro lado, a fiscalização para evitar a formação de novas áreas de risco e de degradação da vegetação, é um tema menos abordado nas propostas.

A regularização de áreas continua a ser um problema, pois as propostas seguem no caminho da regularização forçada, sem considerar os riscos e problemas futuros à sociedade.

A busca da sustentabilidade, equidade, redução de risco e de uma sociedade resiliente passa pela superação do patriarcalismo cultural (BOFF, 2010), sendo preciso 
criar oportunidades para a participação das mulheres na construção de sociedade mais justa.

A redução dos desastres socioambientais está ligada a prioridades políticas. Os candidatos dos municípios avaliados têm incorporado em suas propostas medidas para planejar melhor as áreas urbanas e de expansão, de forma a reduzir os riscos e promover a conservação dos recursos naturais, fundamentais para o equilíbrio ambiental das cidades e para a qualidade de vida da população.

\section{Referências}

CALDAS, Nisimar Martinez Pérez. Novos instrumentos da política urbana: alcance e limitações das ZEIS. 2009, 260p. Tese (Doutorado em Arquitetura e Urbanismo) Universidade de São Paulo, Faculdade de Arquitetura e Urbanismo. São Paulo, 2009.

BARBOSA, Sônia Regina da Cal Seixas; FORMAGIO, Cessimar de Campos, BARBOSA, Rebeca Veiga. Áreas protegidas, uso e ocupação do solo, qualidade de vida e turismo no litoral norte paulista: algumas reflexões sobre o município de Ubatuba. Caderno Virtual de Turismo. v. 10, n. 2, 2010.

BOFF, Leonardo. Cuidar da terra, proteger a vida: como evitar o fim do mundo. Rio de Janeiro: Record, 2010.

COUTINHO, Marcos Pellegini et al.. O Código Florestal Atual (Lei Federal n.12.651/2012) e suas implicações na prevenção de desastres naturais. Sustentabilidade em Debate, v. 4, n. 2, p. 237-256, 2013.

DENALDI, Rosana. Plano de ação integrada em assentamentos precários. In: Ministério das Cidades, Aliança de Cidades (Curso a distância). Ações integradas de urbanização de assentamentos precários. Edição Bilíngue, Brasília / São Paulo: Ministério das Cidades / Aliança de Cidades, $1^{\text {a }}$ Ed., 2010. p. 11-32.

GROSTEIN, Marta Dora. Metrópole e expansão urbana: a persistência de processos “insustentáveis". São Paulo Perspec., São Paulo, v.15, n.1, p. 13-19, 2001. Disponível em: http://dx.doi.org/10.1590/S0102-88392001000100003> Acesso em: 13 dez. 2016

\section{INSTITUTO BRASILEIRO DE GEOGRAFIA E ESTATÍSTICA. Perfil dos municípios brasileiros} 2013. Rio de Janeiro: IBGE, 2014. Disponível em:

<ftp.ibge.gov.br/Perfil_Municipios/2013/munic2013.pdf >. Acesso em: 16 dez. 2015. 
KOBIYAMA, Masato et al.. Hydrological disasters reduction: lessons from hydrology. In: SENS, Maurício Luiz \& MONDARDO, Renata Iza (Org.). Science and technology for environmental studies: experiences from Brazil, Portugal and Germany. Florianópolis: UFSC, 2010. p. 49-72.

KOBIYAMA, Masato; MICHEL, Gean Paulo; GOERL, Roberto Fabris. Relação entre desastres naturais e floresta. Revista GEONORTE, v. 1, n. 6, p. 17-48, 2012.

LIMA, Juliana Macedo de. Democracia no Brasil e participação das mulheres na política: algumas barreiras para o desenvolvimento democrático. In: SEMINÁRIO INTERNACIONAL DE CIÊNCIA POLÍTICA, I, Porto Alegre, set. de 2015. Anais... Porto Alegre: Universidade Federal do Rio Grande do Sul, 2015.

LONDE, Luciana de Resende et al.. Presença de órgãos de defesa civil nos municípios brasileiros: necessidade para lidar com vulnerabilidades e riscos socioambientais. In: ENCONTRO INTERNACIONAL DE VULNERABILIDADES E RISCOS SOCIOAMBIENTAIS, 1, 2014. Rio Claro. Anais...Rio Claro: UNESP, 2014, p. 369-376.

MARICATO, Ermínia. O Estatuto da Cidade Periférica. In: CARVALHO, Celso Santos \& ROSSBACH, Ana Claudia (Org.). O Estatuto da Cidade: comentado. São Paulo: Ministério das Cidades / Aliança das Cidades, 2010. p. 5-22.

OLIVEIRA FILHO, Paulo Costa de et al.. A importância das áreas verdes em uma cidade de pequeno porte: estudo de caso na cidade de Irati-PR. REVSBAU, Piracicaba-SP, v. 8, n. 1, p. 89-99, 2013.

SÃO PAULO. Serra do Mar e Mosaicos da Mata Atlântica: uma experiência de recuperação socioambiental. $1^{\text {a }}$ edição. São Paulo: KPMO Cultura e Arte, 2014. 136 p. Disponível em: < http://arquivos.ambiente.sp.gov.br/serradomar/2016/12/AF_P_MIOLO_Livro-Serra-do-Mar2.pdf>. Acesso em: 17 mai. 2017.

SORIANO, Érico et al.. Avaliação de propostas de candidatos a prefeitos em relação aos riscos de desastres naturais. Soc. e Nat., Uberlândia, v. 25, n. 3, p. 525-542. Set./dez., 2013.

SPARANDELI, Daniel Iozzi. Dinâmica e análise do crescimento, dos vazios e das áreas verdes urbanas de Atibaia, SP. 2010, 84 p. Dissertação (Mestrado em Ciências em Meio Ambiente e Recursos Hídricos) - Universidade Federal de Itajubá, Programa de Pósgraduação em Meio Ambiente e Recursos Hídricos, Itajubá, 2010.

SPINAZZOLA, Patrícia Cezário Silva. Impactos da regularização fundiária no espaço urbano. 2008, 162 p. Dissertação (Mestrado em Habitat) - Universidade de São Paulo, Faculdade de Arquitetura e Urbanismo, São Paulo, 2008. 
TUCCI, Carlos Eduardo Morelli. Gestão de Águas Pluviais Urbanas. In: TUCCI, Carlos

Eduardo Morelli (Org.). Ministério das Cidades - Global Water Partnership - Wolrd Bank Unesco, 2005. Disponível em: <

https://labgeologiaambiental.jatai.ufg.br/up/285/o/Gest\%C3\%A30_de_Aguas_Pluviais_.PD F?1370615799>. Acesso em: 12 jan. 2017. 